\title{
Thermal Aging of Twaron Fibers
}

\author{
ANJANA JAIN ${ }^{1}$ \\ KALYANI VIJAYAN \\ Materials Science Division, NationalAerospace Laboratories, Bangalore-560 017, India
}

(Received 25 September 2002; accepted 21 November 2002)

\begin{abstract}
The residual effects of thermal aging on Twaron fibers have been studied using X-ray diffraction, weight analysis, scanning electron microscopy and tensile testing. X-ray data from isothermally aged fibers indicate the introduction of changes at the level of the crystal lattice, which include reduction in crystallinity, variations in 29 values, half width and azimuthal spread of reflections. Isothermal aging also introduces weight loss. Examination of the surface of fibers has shown that damages in the form of holes, materials deposits, etc., are introduced by isothermal aging. These data on Twaron further show that the thermally induced effects are controlled by two parameters: temperature $T$ and cumulative exposure time to $T$, i.e. $t_{\text {cum }}(T)$. Among the tensile properties, the tensile strength is found to be more sensitive to thermal aging than modulus. In addition to the structural studies on the thermal aging behavior of Twaron, a one-to-one comparison has also been attempted between the tensile behavior of Twaron and Kevlar 49 fibers, which are also made up of the same polymer.
\end{abstract}

Key words: Twaron, thermal aging, X-ray diffraction

\section{INTRODUCTION}

Twaron fibers are made up of poly ( $p$-phenylene terephthalamide) or PPTA, the structural formula of which is shown below:

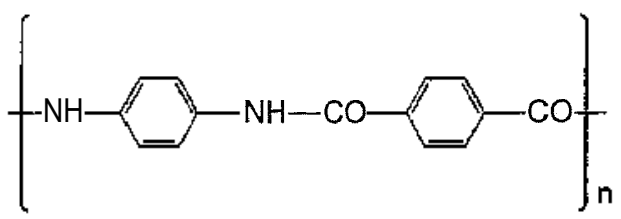

Twaron is a high strength, high modulus, light weight aramid fiber with good thermal stability and high impact resistance. Its unique combination of properties means that Twaron can be used in high performance composites for structural and ballistic applications [1]. It must be mentioned that Kevlar fibers, which are commercialized by DuPont Inc., USA are also made up of PPTA [2], as Twaron is. 
In the past, extensive studies have been carried out on the effect of thermal exposures on Kevlar 49 fibers [3-13]. Interestingly, the initial tensile modulus, strength and percentage elongation at the break, namely, $2.92 \mathrm{GPa}, 64.3 \mathrm{GPa}$ and $4.3 \%$ respectively, of Twaron fibers used in the present study differ from those of Kevlar 49 fibers (3.01 GPa, $92.6 \mathrm{GPa}$ and $3.4 \%$, respectively). Since Twaron fibers are used extensively in the aerospace industry, it is also of interest to know the thermal aging behavior of Twaron fibers. It must be emphasized that, although both Twaron and Kevlar fibers are made up of the same polymer PPTA, they are from different agencies and are also characterized by different initial tensile properties. These differences in the initial tensile properties can affect the thermal aging behavior. From these points of view, thermal aging studies on Twaron fibers were carried out. Attention has been focused on deciphering the structural changes introduced by thermal aging. Both crystal structural and macro structural changes have been examined. A one-to-one comparison between the tensile behaviors of Twaron and Kevlar 49 fibers has also been attempted.

\section{EXPERIMENTAL DETAILS}

The Twaron fibers used in the present study were provided by the kind courtesy of Akzo Nobel, The Netherlands. The Kevlar 49 fibers used were those made commercially available by DuPont Inc., USA.

The temperatures $(T)$ chosen for aging Twaron fibers were $300,400,450$ and $500^{\circ} \mathrm{C}$. The duration of the cumulative exposures, $t_{c u m}(T)$, varied with the value of $T$, It must be pointed out that the choice of $T>300^{\circ} \mathrm{C}$ was deliberate and was intended to enable accelerated data collection, which in turn could be extrapolated or interpolated to provide user-relevant information. The decomposition temperature, $T_{d}$, reported [14] for Twaron is $500^{\circ} \mathrm{C}$.

Unconstrained bundles of fibers, $\sim 50 \mathrm{~mm}$ in length and $\sim 2 \mathrm{~mm}$ thick, were aged in air, using a tubular resistance furnace with nichrome as the heating element. By employing a PID (proportional, integral and differential) controller, the temperature of the furnace could be controlled to an accuracy of $\pm 1^{\circ} \mathrm{C}$. The temperature of the sample was measured using a chromel-alumel thermocouple. Fibers encased in a quartz tube were slid into the constant temperature zone (CTZ) of the furnace, pre-stabilized at a chosen temperature. At various stages of aging, the samples were taken out, air cooled and characterized. The techniques used for the characterization of fibers prior to and at various stages of heat treatment were X-ray diffraction, scanning electron microscopy (SEM), weight analysis and tensile testing. It must be mentioned that separate bundles of fibers were used for the various types of analyses. For example, the bundle used for X-ray analysis was different from that used for SEM investigations. At every stage of the analysis, extreme care was exercised to ensure that the samples were not contaminated by dust or dirt and were not subjected to any other type of mishandling.

Wide-angle X-ray diffraction patterns were recorded in the reflection geometry, using a Philips powder diffractometerwith a proportional counter and a graphite monochromator in the diffracted beam. $\mathrm{CuK} \alpha$ radiation was used. The samples were rotated at the 
rate of $1 / 4^{\circ}$ per minute and a chart speed of $10 \mathrm{~mm}$ per minute was used. It must be emphasized that the geometry of the Philips diffractometerpermitted the recording of only the equatorial patterns. The parameters estimated from the X-ray diffraction patterns were $2 \theta_{\max }$, full width at half maximum $(\omega)$ and integrated intensity $(I)$. Values of $2 \theta_{\max }$ were determined by the mid-point chord extrapolation method [15]. co was measured by using a scale and / was determined by measuring the area under the entire diffraction pattern using a digitizer and an Autocad system. The overall intensity in any diffraction pattern is closely related to the crystallinity of the sample [16]. In the present study we are concerned only with relative changes in crystallinity and, as such, absolute values of $\mathrm{X}$-ray crystallinity were not determined. However, the ratio $k=I_{t}(T) / I_{0}$ was used to estimate values of the residual crystallinity of heat-treated samples. In this expression, $I_{0}$ and $I_{t}(T)$ correspond to the integrated intensities of the patterns recorded from fibers prior to and at various stages of heat treatment, respectively. In addition to the diffractometer recordings, transmission Laue photographs were also recorded from some of the heattreated samples. The photographs were used primarily to identify changes in the azimuthal spread $\left(\beta_{a z i}\right.$ of reflections. The extent of misalignment can be estimated by the angular spread of reflections.

To examine the thermally induced changes in the initial weight, the fibers were weighed before and at various stages of thermal aging. A Sartorious analytical balance, which can read down to $0.0001 \mathrm{~g}$, was used to estimate the weights. When the heat-treated samples were taken out of the furnace, they were cooled in a dessicator for about $30 \mathrm{~s}$ and were weighed immediately afterwards. The percentage change in weight introduced by thermal exposures was estimated from the following relation:

$$
\text { percentage change in weight }=\left(w_{o}-w_{t}\right) / w_{o} \times 100 .
$$

Here, $w_{o}$ and $w_{t}$ are the weights of the sample prior to and after thermal exposure, respectively. Each weight value reported in this paper is an average obtained from examining the weight of at least three samples, which have been treated similarly.

The surface characteristics of fibers, both prior to and after thermal exposure, were studied using a Jeol scanning electron microscope. To examine the features of fractured ends, some of the fibers were fractured in tension in a water medium. Prior to scanning, the samples were coated with gold to make them conductive. In order to avoid the introduction of artifacts due to manual or mishandling of the samples, extreme care was taken. The portion of the fiber, which was examined under the microscope, was never allowed to have contact with fingers or any other object. Also, to prevent contamination by dust from the atmosphere, samples, which were selected for observation under the microscope, were always kept covered inside a bell-jar until they were eventually moved to the stage of the microscope.

The tensile testing was conducted on a single fiber using a Zwick universal testing machine. Separate bundles of both Twaron and Kevlar 49 fibers were exposed progressively to $150,250,300$ and $350^{\circ} \mathrm{C}$. At each of the chosen temperatures, the residence time was $1 \mathrm{~h}$ after which the tensile properties were analysed. For example, after 


\section{A. JAIN and K. VIJAYAN}

exposure to $150^{\circ} \mathrm{C}$ for $1 \mathrm{~h}$, a few fibers from the bundle were removed for tensile testing and the rest of the bundle was used for further heating. Prior to the tensile testing, the diameters of individual fibers were estimated, using an optical microscope. The diameter of each fiber was measured at five different points along the length and the average value was estimated. A gauge length of $25 \mathrm{~mm}$ was selected. The fibers were pulled at a rate of $2.5 \mathrm{~mm}$ per minute and a chart speed of $60 \mathrm{~mm}$ per minute was used to record the load-extension curves. Loads in the range $0-0.5 \mathrm{~N}$ were applied to the fibers using an appropriate load cell. From the load-extension curves, values of tensile strength and tensile modulus and percentage elongation at the break were obtained. Tensile testing could not be carried out for samples exposed to temperatures greater than $350^{\circ} \mathrm{C}$, because at these temperatures the fibers became too brittle for handling.

\section{RESULTS AND DISCUSSION}

\subsection{Effect of Thermal Exposures on Twaron Fibers}

\subsubsection{X-ray analysis}

The crystal structural features as derived from X-ray diffraction data are presented in this section.

\section{(a) Intensity}

Diffraction profiles recorded prior to and after thermal exposure to temperatures of 300$500^{\circ} \mathrm{C}$ are presented in figures 1 (a)-(d). The equatorial reflections observed in the X-ray diffraction pattern from Twaron, at $2 \theta$ values of $\sim 20.6^{\circ}$ and $22.9^{\circ}$ correspond to (110) and (200), respectively. The indexing is based on a monoclinic unit cell with approximate unit cell dimensions of $a=7.89, b=5.18$ and $c$ (unique axis) $=12.9 \AA$, $y=90^{\circ}$ [17]. The recording of the equatorial diffraction patterns was hence confined to the 20 range of $15-$ $27^{\circ}$. The present analysis is based essentially on the thermally induced changes manifested by these two reflections.

The striking feature of the diffraction patterns is that, for a chosen temperature, the overall intensity reduces with the increase in the cumulative exposure time. Eventually, a stage is reached when the pattern does not include the initially observed reflections. It must be recalled at this stage that the two reflections depicted in figures 1 (a)-(d) are the two most intense reflections in the entire diffraction pattern from PPTA and they have been rendered 'unobservable' by the chosen cumulative exposures to various temperatures. The stage at which the intensities of the reflections are not observable, i.e. they merge with the background, may be referred to as the zero crystallinity state of the sample. Values of the residual crystallinity $(k)$ estimated from the observed values of integrated intensities have been marked in figures $1(\mathrm{a})-(\mathrm{d})$. The $k$ values provide quantitative evidence for thermally induced progressive diminution and an eventual total loss in the residual crystallinity of the sample. As may be observed from the diffraction profiles, at $300^{\circ} \mathrm{C}$, it requires slightly more than $350 \mathrm{~h}$ of exposure to reach the state of zero residual crystallinity. The duration of the cumulative exposure needed for reaching this state is referred to as $t_{100}$. At 400, 450 and 


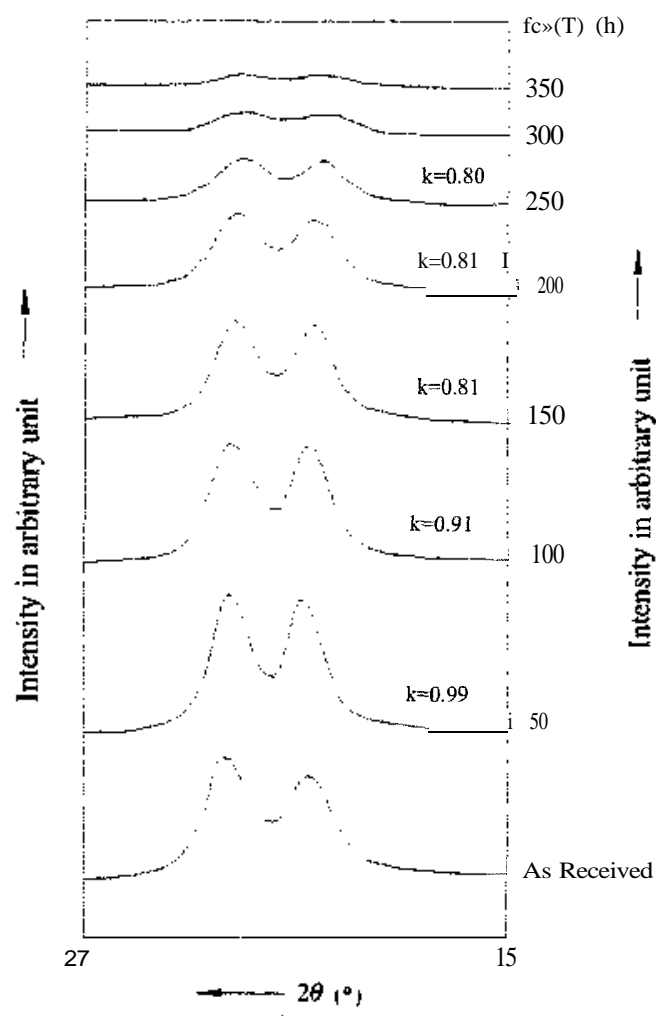

(a)

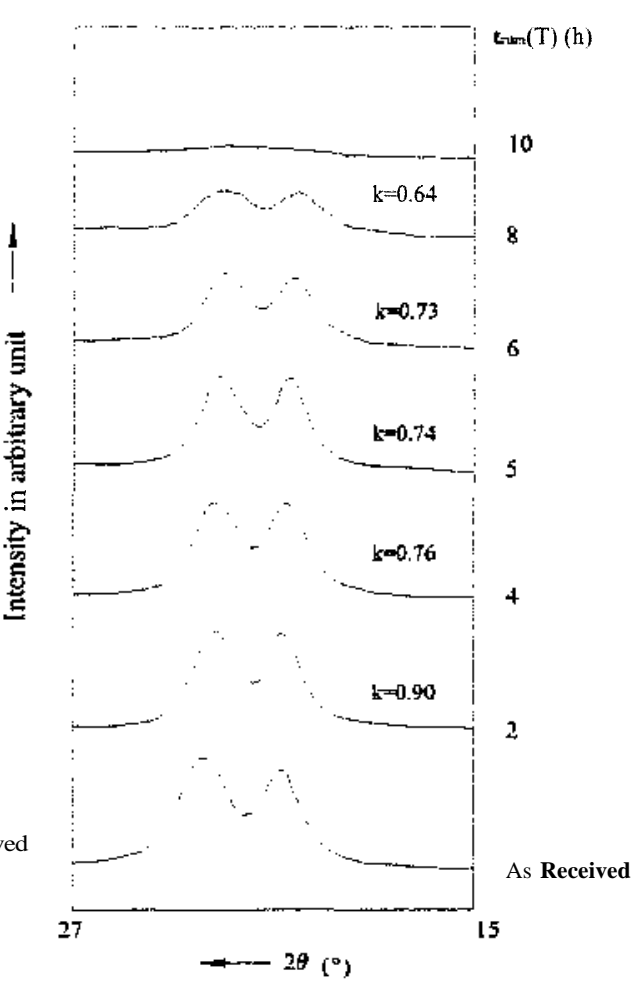

(b)

Figure 1. X-ray diffraction profiles recorded prior to and at various stages of exposure to (a) $300^{\circ} \mathrm{C}$ and (b) $400^{\circ} \mathrm{C}$.

$500^{\circ} \mathrm{C}$, the time needed to lead to the state of zero residual crystallinity is understandably less, $\sim 10,2$ and $1 \mathrm{~h}$, respectively.

It must be pointed out that on this timescale, the zero crystallinity state, as identified from the present set of experiments, is likely to be slightly underestimated. The diffraction patterns analysed in the present study have been recorded using a proportional counter as a detector. If improved detectors were available, the terminal, zero intensity state marked in each set of diffraction patterns in figures 1(a)-(d) might have been observed as very low intensity reflections. Eventually, with further continuation of the cumulative exposure at each of the chosen temperatures, the zero crystallinity state would have been reached, but beyond the values of $t_{\text {cum }}(T)$ noted in the present set of experiments. On account of the limitations imposed by the 'not so very sophisticated' detector system, the $t_{100}$ values identified from the present study are likely to be slightly underestimated, although not far away from the actual value. 
110 A. JAIN and K. VUIAYAN

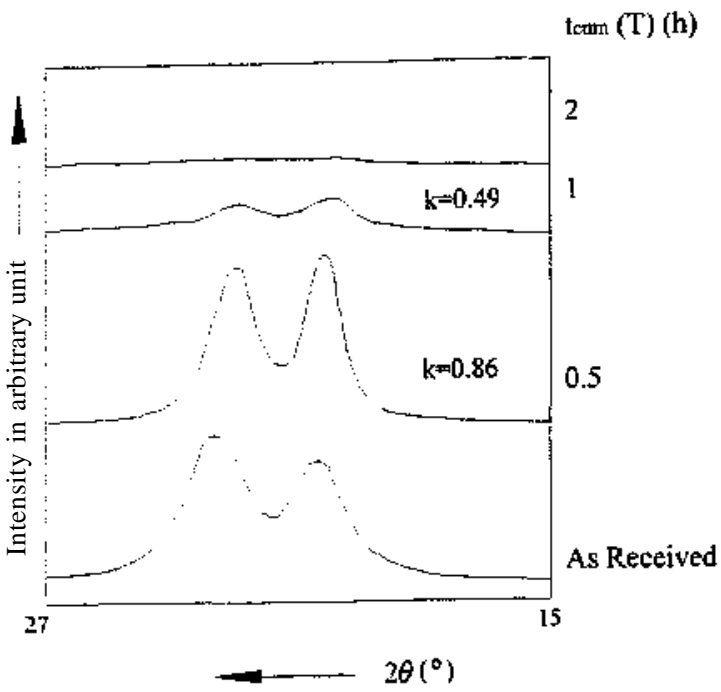

(c)

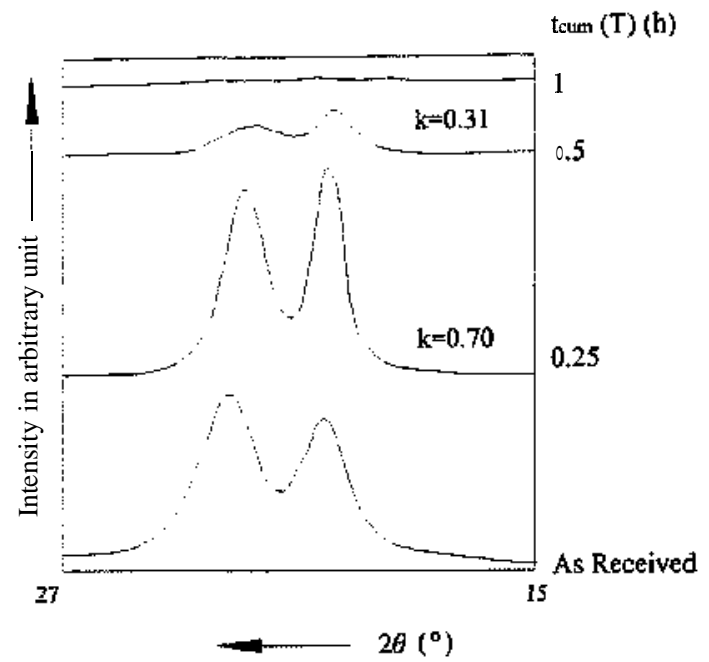

(d)

Zi gure 1 . X.ray dfiraction profiles recordsd prior to and at various stags8 of exposure to (c) $450^{\circ} \mathrm{O}$ and (d) $500^{\circ} \mathrm{C}$. 


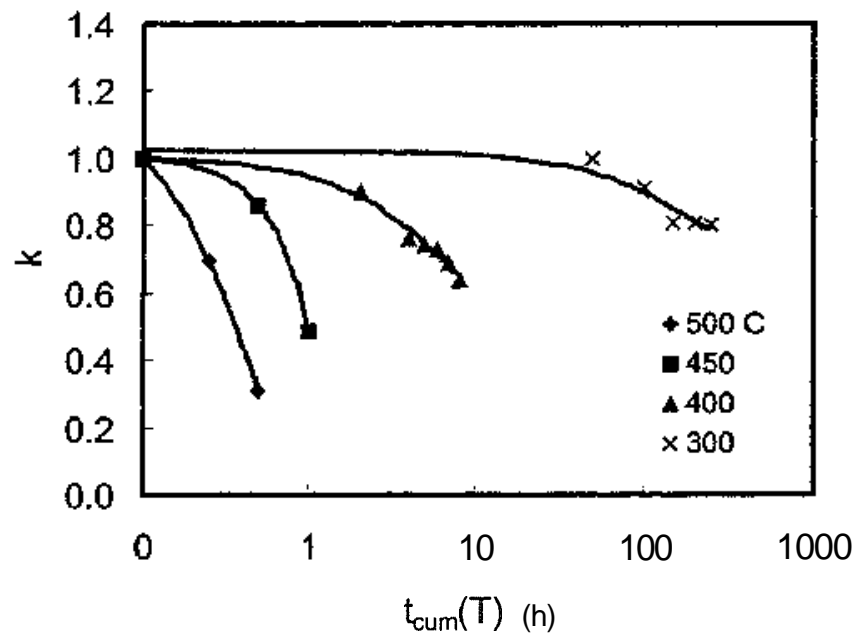

Figure 2. Variation of residual crystallinity, $k$, with $t_{c u m}(T)$ and $T$.

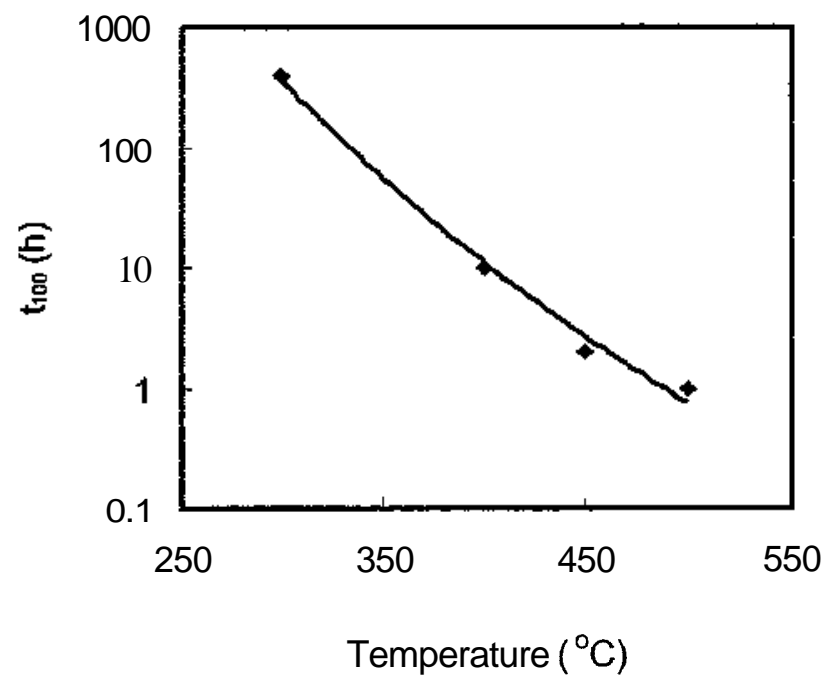

Figure 3. Variation of the parameter $t_{100}$ with temperature. 
Figure 2 is a consolidated depiction of the variation of $k$ at various temperatures. As expected, the variation is comparatively slow at lower temperatures. Figure 2 can be used to predict the crystallinity of heat-treated samples. Figure 3 shows the variation of the parameter $t_{100}$ with temperature. For the temperature range chosen, the curve deviates only slightly from linearity. This is user-relevant information because, by extrapolation or interpolation of curves, cumulative exposure time for $100 \%$ loss in crystallinity can be calculated.

The crystallinity of a fiber can indeed affect its tensile properties. The reduction in crystallinity as established from the present study suggests that the tensile properties of the thermally aged fibers are also likely to be adversely influenced.

Another interesting feature observed in the diffraction patterns concerns the relative values of the peak intensities of the reflections (200) and (110). Prior to heat treatment, the intensities manifest the following inequality: $7(200)>I(110)$. Thermal exposures seem to affect this inequality. The patterns in figure 1 show that for the heat-treated samples $I(200)$ $\approx I\left(110\right.$ ). Figure 1 (d) shows an interesting reversal: after $0.25 \mathrm{~h}$ of exposure to $500^{\circ} \mathrm{C}$, $I(110)>7(200)$. As is well known, the intensity distribution in a diffraction pattern is related to the atomic arrangement. The above-mentioned reversal of the peak intensities of the first two most intense reflections from PPTA suggests that heat treatment perhaps introduces slight changes in the atomic or molecular arrangement in the crystal structure. Comparison of the patterns corresponding to 300 and $500^{\circ} \mathrm{C}$ suggests that the intensity reversal is preceded by an equality of the type $7(200) \approx 7(110)$. At higher temperatures, the reversal occurs readily.

\section{(b) 20 values}

A comparison of the diffraction patterns recorded from Twaron fibers prior to and after heat treatment shows that thermal exposure left subtle residual effects on the 29 values, i.e. the 26 values become slightly shifted from the initial values. Figures $4(a)$ and (b) depict the observed variations.

It is also conspicuous that, although both (200) and (110) are equatorial reflections, the thermally induced reductions in the $2 \theta_{(200)}$ values are more than the changes in the $2 \theta_{(110)}$ values. Such a disparity can be understood by examining the crystal structure of PPTA. Figure 5 is a representation of the molecular arrangement of PPTA chains in the crystallographic $b c$-plane. The PPTA chains, which assume a fully extended, all trans conformation, are oriented along the crystallographic c-direction. Adjacent chains interact by hydrogen bonds, marked by dashed lines in figure 5 . Thus a layer structure stabilized primarily by interchain hydrogen bonds evolves in the crystallographic $b c$-plane. Such layers are stacked periodically along the crystallographic $a$-direction. Interaction between adjacent layers is primarily of the van der Waal's type and to some extent pi-electron interactions also exist. The higher sensitivity of the (200) reflection can be correlated with the weak van der Waal's interactions, which exist along the crystallographic $a$-direction.

It is found that, for both equatorial reflections, the 26 values decrease with thermal aging. Thus, the residual effect of thermal exposures is an expansion of the basal plane dimensions. Figures 6(a) and (b) depict the variation in the $a$ and $b$ values. 


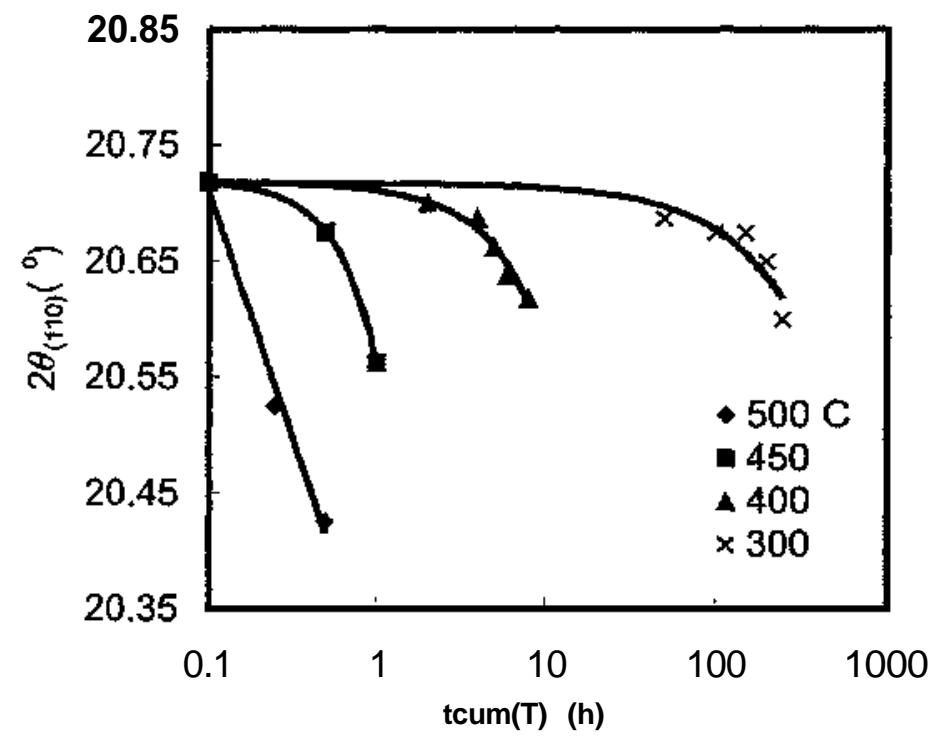

(a)

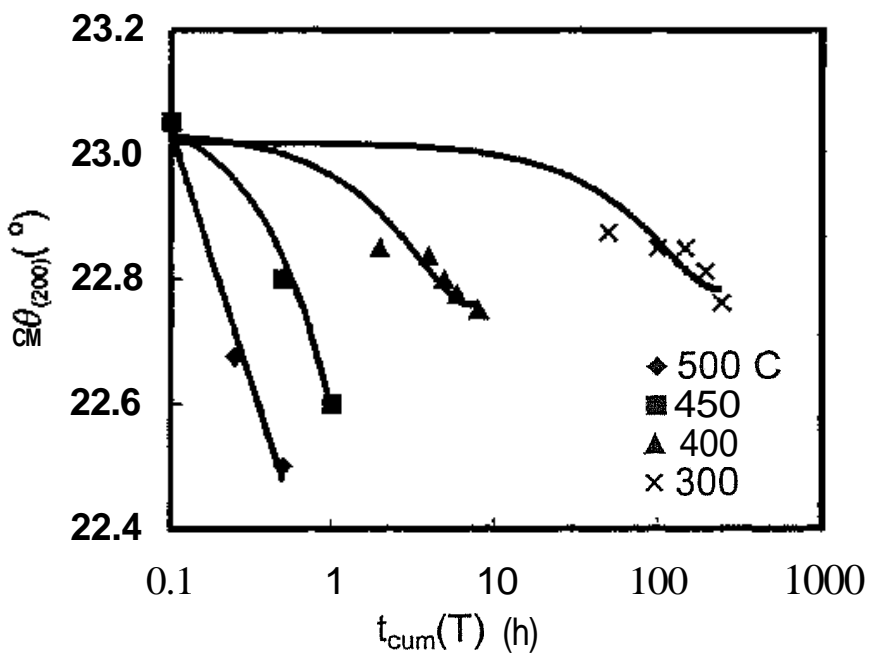

(b)

Figure 4. Variation of (a) $2 \theta_{(110)}$ and (b) $2 \theta_{(200)}$ values with $t_{c u m}$ (T) and $T$. 


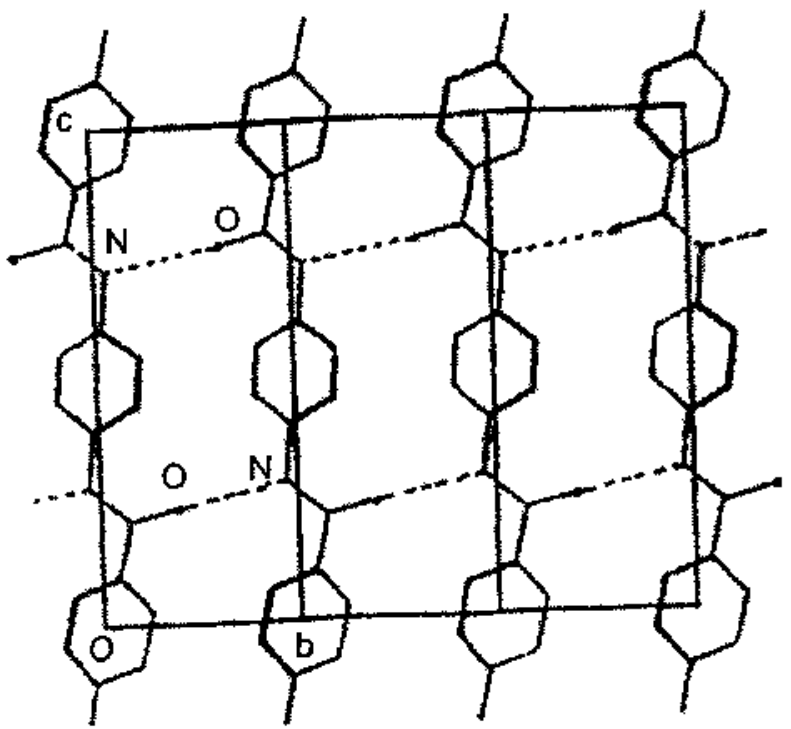

Figure 5. Molecular arrangement in the crystallographicfcc-plane [17].

The expansion manifested by thermally aged samples thus appears to be the residual effects of thermal expansion, which have occurred during exposure to the respective temperatures. It must be mentioned that Jain and Vijayan [13] have earlier observed a similar expansion of the basal plane by heating Kevlar fibers using an in situ heating arrangement. The present study shows that part of the expansion is retained as residual effects.

A parameter, which is dependent on the 29 values of the equatorial reflections, is the angular separation between them, i.e.

$$
\mathrm{A}(20)=2 \theta_{(200)}-2 \theta_{(110)} .
$$

It has been reported earlier that the tensile strength of Kevlar 49 fibers is closely related to the above-mentioned angular separation $\Delta(2 \theta)$ [18]. A closing up of the equatorial reflections (200) and (110) is an indication of reduction in tensile strength. Thermally induced changes in the 20 values of the equatorial reflections recorded from Twaron suggest that the angular separation and, consequently, the tensile strength are affected by thermal exposure. Figure 7 depicts the observed closing up of the equatorial reflections. It may be noted that, at all the temperatures selected, the first exposure is responsible for the large drop from the initial value of $\mathrm{A}(20)$. Subsequent exposures cause further reductions but they are conspicuously much less. As mentioned earlier, the $2 \theta_{(200)}$ values are more sensitive to thermal exposure than the $2 \theta_{(110)}$ values. As such, the major contribution to the reductions shown in figure 7 is from the reflection (200). The data in figure 7 suggest 


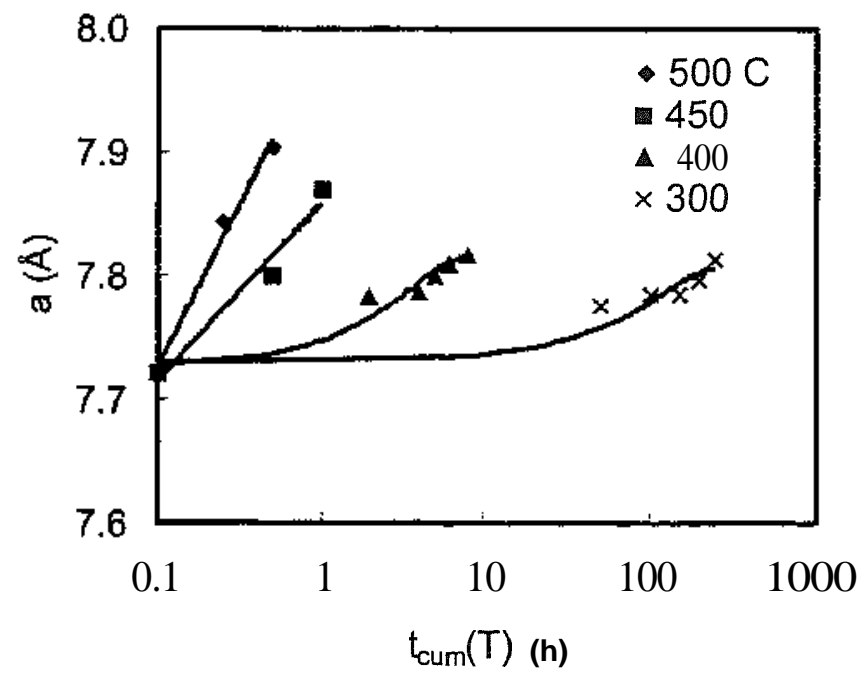

(a)

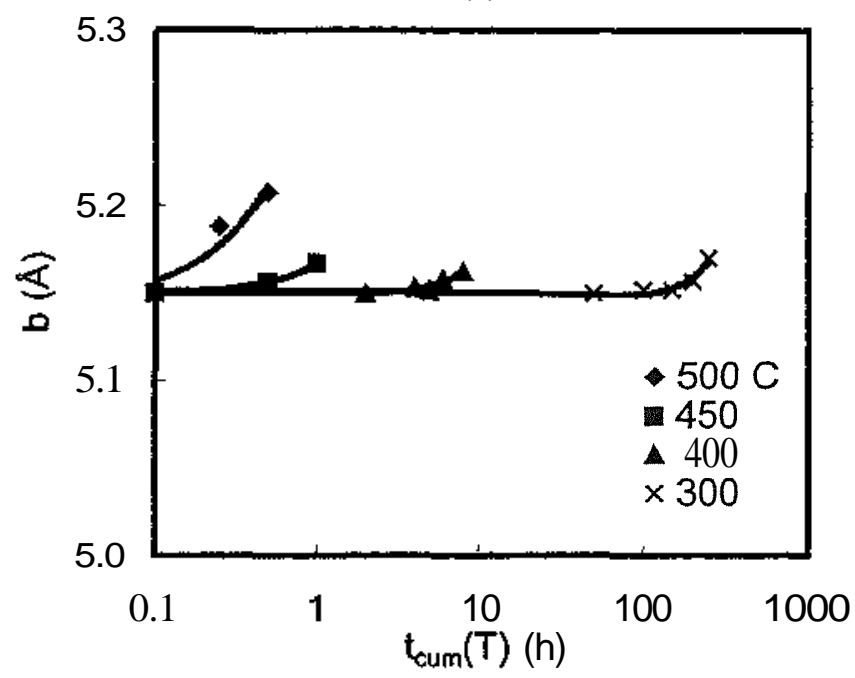

(b)

Figure 6. Variation of the unit cell dimension (a) a and (b) with $t_{c u m}(T)$ and $T$. 


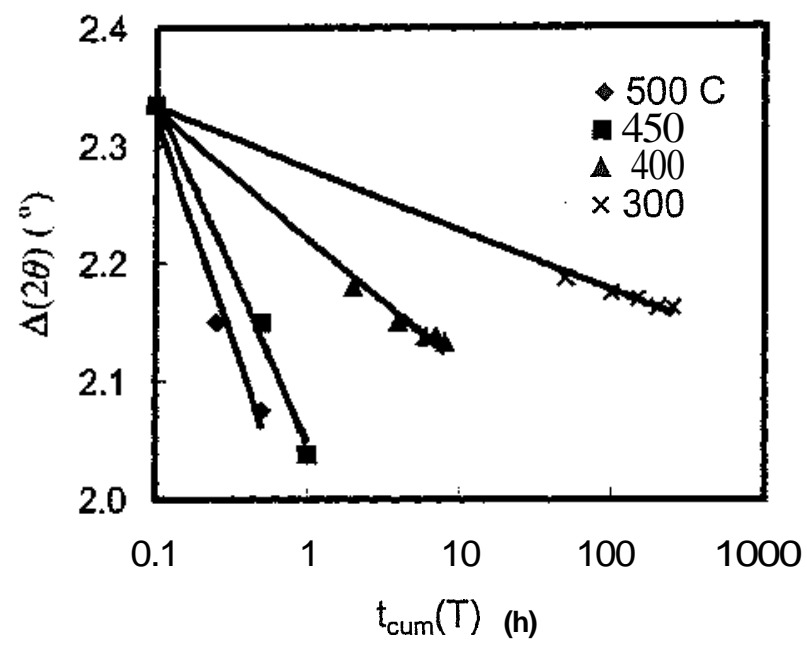

Figure 7. Variation of the $\mathrm{A}(20)$ values with $t_{\text {cum }}(T)$ and $\mathrm{T}$.

that exposures to higher temperatures are likely to cause enhanced deterioration in tensile strength than at lower temperatures. This indeed is what can be expected.

The role of the parameter $t_{\text {cum }}(T)$ can also be appreciated from figure 7 . When the fiber is exposed to a chosen temperature in a cumulative fashion, the reduction in angular separation is enhanced. Consequently, the tensile strength may also be expected to manifest a progressive decrease with time, for a constant value of $T$.

(c) Half width $(\omega)$

Thermal aging of Twaron fibers introduces changes in the half widths of reflections. Figures 8(a) and (b) show the fractional variation in the half width values of the two equatorial reflections recorded from samples aged at various temperatures. The conspicuous feature is that, irrespective of the temperature, the first thermal exposure always introduces sharpening, i.e. reduction in the half width value. Also, the extent of sharpening is more for the reflection (110) than for (200). Similar preferential sharpening of the (110) reflection has been observed earlier in heat-treated Kevlar 49 fibers, and has also been correlated with the concentration of non-bonded intermolecular interactions along the crystallographic (110) set of planes [4, 7]. As is well known, the half width of a diffraction profile is related to the crystallite size and the microstrain [16]. The initial sharpening (figures 8(a) and (b)) suggests that the first thermal exposure has the effect of a sort of annealing in which the inherent strains in the sample are relieved. Subsequent thermal aging, however, introduces progressive broadening suggesting the fragmentation of crystallites and/or the introduction of microstrain. Indeed, progressive degradation and an eventual decomposition of a material could well be expected to be accompanied by a build up of microstrain and reduction in crystallite dimension. 

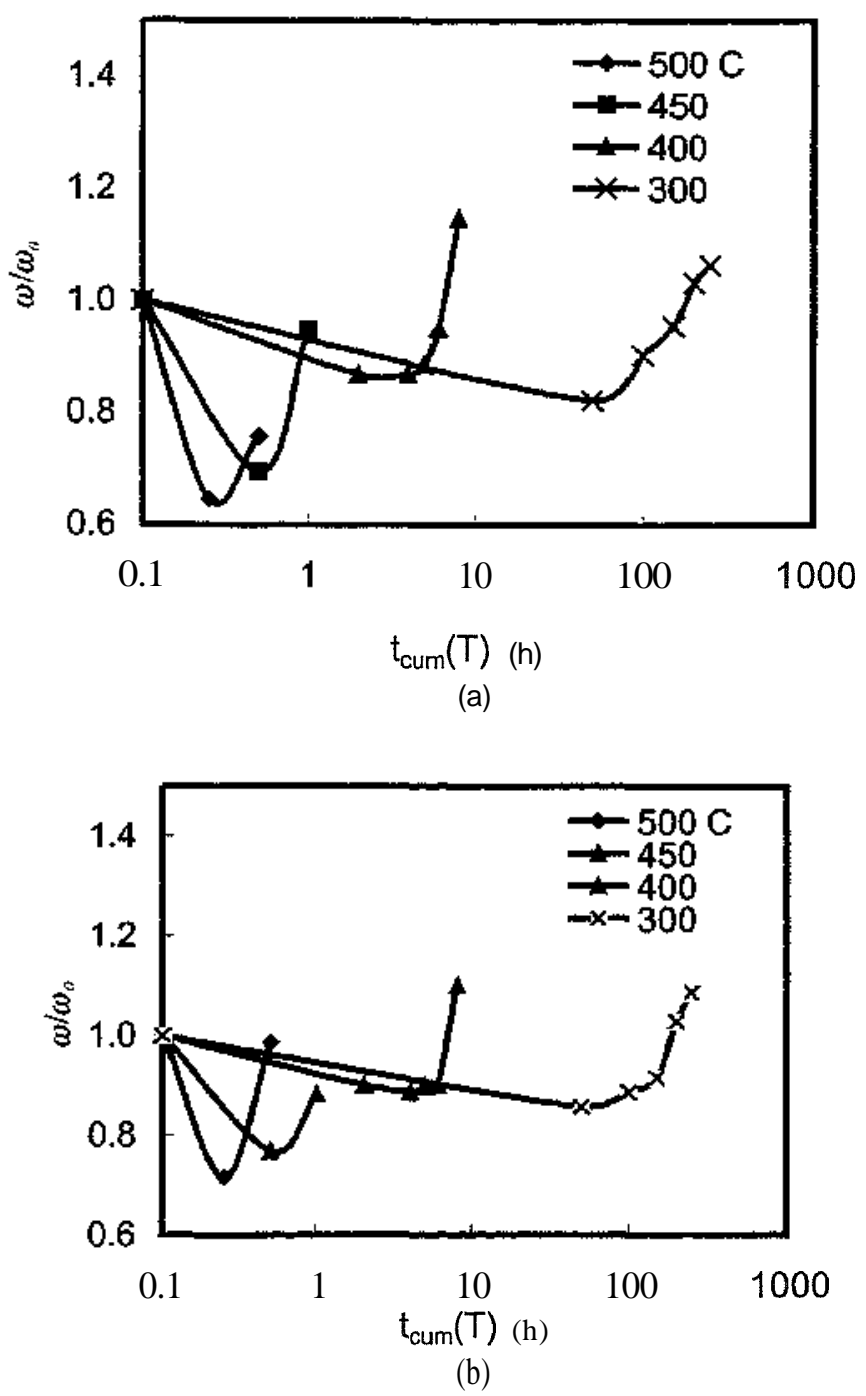

Figure 8. Fractional variation in the half-width values of the reflections (a) (110) and (b) (200) with $T$ and $t_{\text {cum }}(T)$. Here, $\omega_{0}$ and $\omega$ refer to the half width values prior to and after thermal exposures, respectively. 
118 A. JAIN and K. VIJAYAN
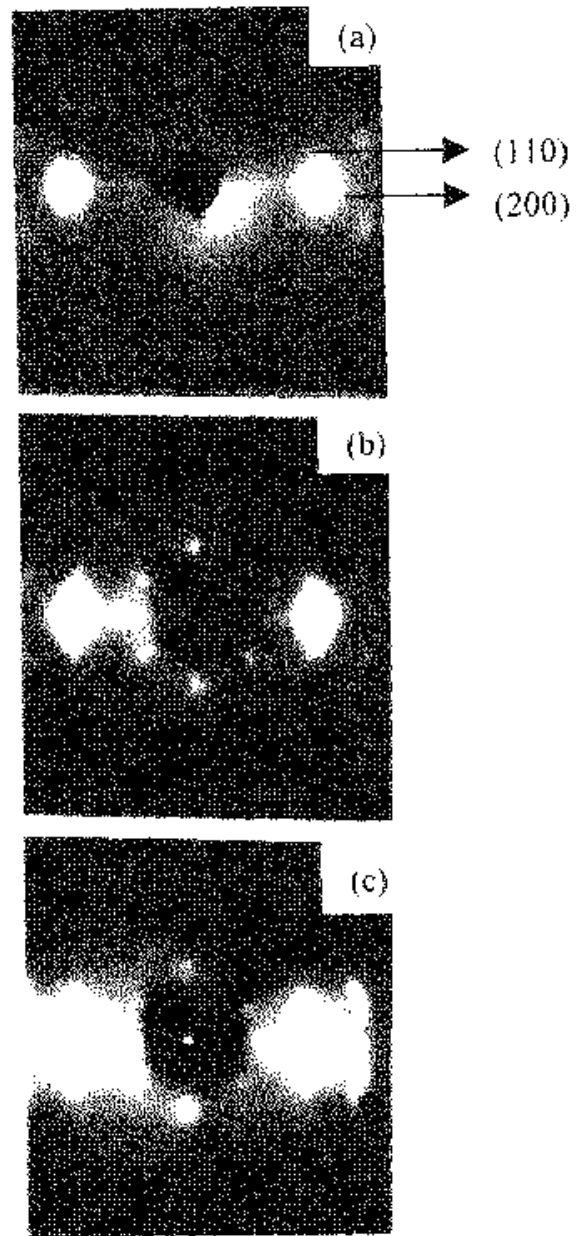

Figure 9. Laue photographs from Twaron fibers: (a) prior to thermal exposure; (b) exposed to 350 . $\mathrm{C}$ for $7 \mathrm{~h} ;$; $(\mathrm{c})$ exposed to $500^{\circ} \mathrm{C}$ for $1 \mathrm{~h}$. 


\section{(d) Azimuthal spread $\left(\boldsymbol{\beta}_{\mathrm{azi}}\right)$}

The azimuthal spreads of reflections from fibers are closely related to the type and extent of molecular alignment about the fiber axis. Figure 9(a) is a typical pattern from Twaron fibers recorded prior to thermal exposure. Here, the indices of the equatorial reflections have also been marked. The photograph indicates that there is a finite angular distribution of the chains about the fiber axis.

A comparison of figures 9(b) and (c) with the spread in figure 9(a) shows that thermal ageing is accompanied by an increase in the azimuthal spread of reflections. Such an increase suggests that the initial molecular alignment is adversely influenced by thermal exposures. Figure 10represents a thermally induced increase in the azimuthal spread $\left(\beta_{a z i}\right)$ of the equatorial reflections. It is noted that an increase in temperature leads to an enhanced misalignment of the chains about the fiber axis. Such misalignment of polymer chains can be expected to have an adverse effect on the initial tensile modulus of the fiber.

\subsubsection{Weight analysis}

Thermally aged Twaron fibers manifest weight loss. The observed residual effects of thermal aging on the weight are depicted in figure 11. The weight loss becomes enhanced with an increase in $T$ as well as $t_{c t m}(T)$ values. Such a reduction in weight implies a corresponding deterioration in the tensile properties as well.

The reduction in weight necessarily implies that the amount of material available for diffraction will also be correspondingly less. In which case, can the observed reduction in intensity, and consequently in crystallinity, described earlier in section 3.1.1, be attributed entirely to the weight loss? This question was addressed by comparing the reduction in crystallinity and weight loss. For example, for the sample exposed to $500^{\circ} \mathrm{C}$ for half an hour the reduction in crystallinity is by $69 \%$ whereas the weight loss is only $19 \%$. Similarly, after one hour of exposure to $450^{\circ} \mathrm{C}$, crystallinity reduces to $49 \%$ and the corresponding weight loss is only $29 \%$. This difference suggests that the reduction in weight contributes only partially to the observed reduction in crystallinity. The loss in crystallinity is always much more than what could be accounted for by the weight loss, thereby indicating that the loss in crystallinity is not a simple consequence of weight loss. The observed reduction in crystallinity is an independent and genuine effect.

Weight loss may be associated with chemical reactions initiated during thermal exposure and the consequent loss of gaseous and other components from the fiber. The present study does not include any in situ chemical analysis of the thermally induced degradation and, as such, no information on the products emanating from thermally aged Twaron is available. It must be mentioned that, in the case of Kevlar fibers, an identification of thermally induced components has been carried out by Kalashnik et al. [19]. As Kevlar and Twaron are both made up of the same polymer, it is likely that similar and identical products evolve from thermally aged Twaron fibers also. 
120 A. JAIN and K. VIJAYAN

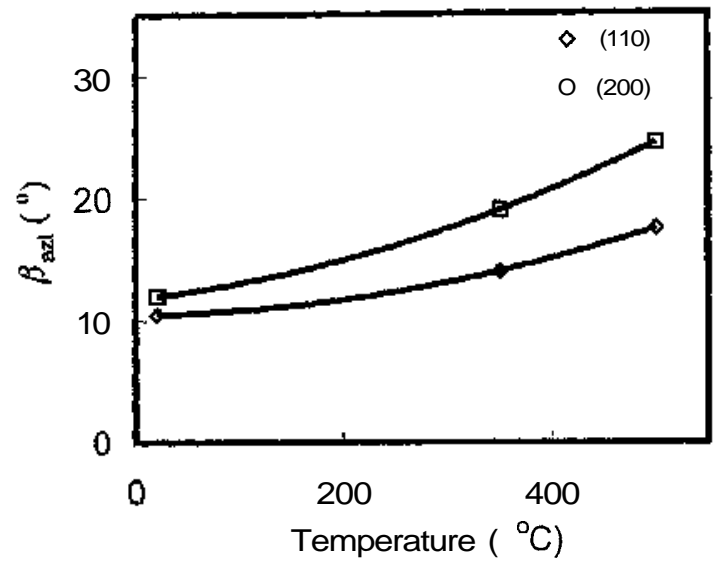

Figure 10. Variation in the azimuthal spread $\left(\beta_{a z i}\right)$ of the equatorial reflections with temperature.

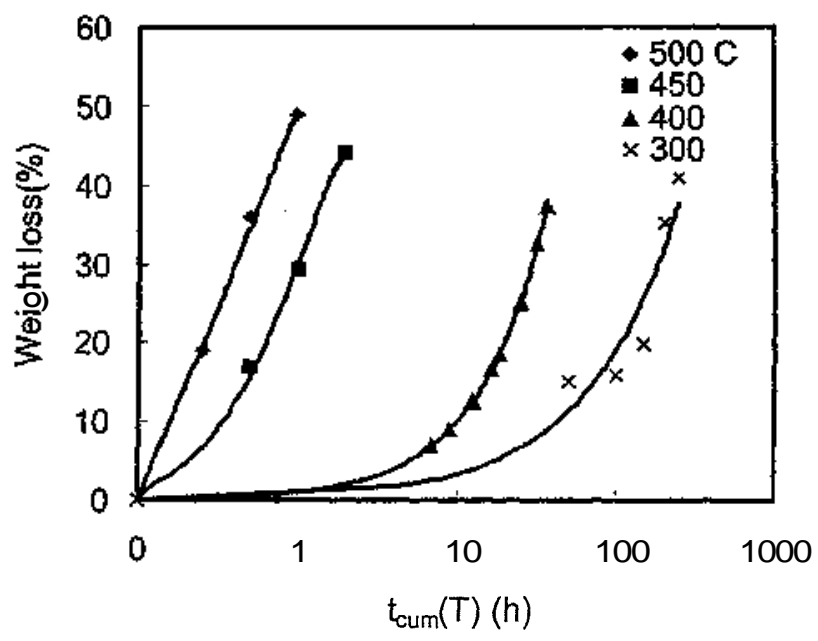

Figure 11. Weight loss (\%) at various temperatures. 


\subsubsection{Surface features}

To appreciate the changes introduced by thermal aging, the surfaces of fibers prior to heat treatment were examined first. Sparsely distributed impurities of the type shown in figure 12(a) were found to be present. The most striking effects of thermal exposure on the surface of Twaron fibers are described below in the order of increasing $T$ values.

$300{ }^{\circ} \mathrm{C}, 200 \mathrm{~h}$ : After experiencing $200 \mathrm{~h}$ of exposure to $300^{\circ} \mathrm{C}$, the surface develops several minute holes distributed along a line (figure 12(b)). Tiny specks of extraneous material are also seen on the surface of the fiber (figures 12(b) and (c)). The fractured fibers captured in figure 12(c) indicate that the initially flexible fiber has turned brittle. The protruding, longish features (figure $12(\mathrm{c})$ ) are suggestive of the fibrillar nature of the fiber.

$400{ }^{\circ} \mathrm{C}, 10 \mathrm{~h}$ : The tiny holes observed at $300^{\circ} \mathrm{C}$ seem to have increased in number and size and they coalesce to produce arc-like openings on the surface (shown by an arrow in figure 13(a)). The micrograph also provides evidence for material loss near the core and the brittle nature of the fracture. It is also found that the amount of surface deposition has increased (figure 13(b)).

$450{ }^{\circ} \mathrm{C}, 2.5 \mathrm{~h}$ and $2 \mathrm{~h}$ : After $2.5 \mathrm{~h}$ of exposure to $450^{\circ} \mathrm{C}$, the holes are far more numerous and appear deeper than those observed at lower temperatures (figure 14(a)). Figure 14(a) also depicts the sponge-like appearance of the surface of a fiber. Thermally induced arclike openings and a wrinkle formed on the surface of a fiber are shown in figure 14(b). It must be mentioned that, very close to decomposition, Kevlar fibers also manifested similar wrinkles on the surface, which were associated with the skin of the fiber $[10,12]$. The micrograph in figure 14(b) also suggests loss of material from near the core of the heat-treated fiber. The holes seen in the micrographs may be associated with evolution of materials - volatile or otherwise - from within the fiber, via the surface. Such an evolution indeed supports the weight loss and reduction in crystallinity described earlier.

$500{ }^{\circ} \mathrm{C}, 1 \mathrm{~h}$ : After exposure to $500^{\circ} \mathrm{C}$, the reported decomposition temperature, the fiber manifests extensive surface damages. The micrographs in figures 15(a) show the 'scrubber wool-like' appearance of the surface. Localized damages have also been found on some fibers. The micrograph in figure 15(b) depicts an example in which the edge, which has been 'eaten away'. Pits, which are larger than the holes observed at lower temperatures, are seen in figure $15(\mathrm{c})$.

The above-mentioned surface damages of various types observed at various temperatures strongly suggest that the tensile properties of thermally aged Twaron fibers are likely to be adversely affected. The data presented in the next section provide conclusive evidence for such deterioration in tensile properties.

At this juncture, it is considered appropriate to consolidate the structural features described thus far and their possible implications on the tensile properties. Table 1 presents the consolidated data. 


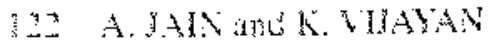

!e!

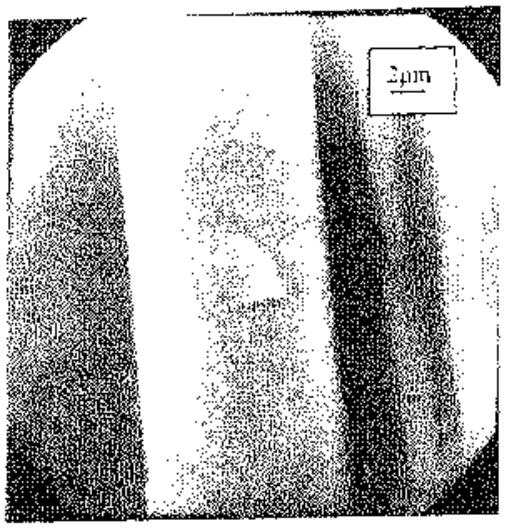

(b)

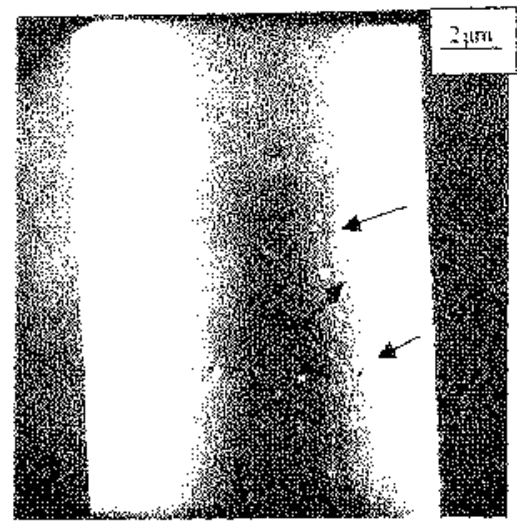

(c)

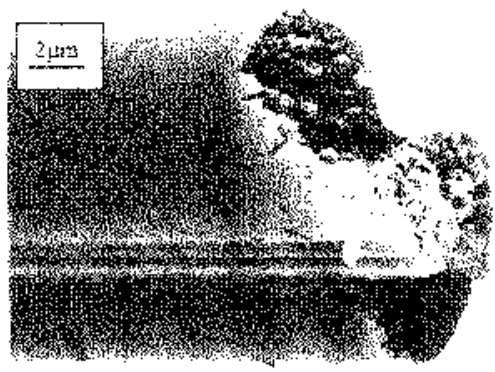

Figure 12 . (a) SEM micrograph from a Twaron fiber prior to thermal exposture. (i) ) is $A$ nich is iph showing holes distributed along a line in a fiber exposed to 300 " $\mathrm{C}$ for $200 \mathrm{~h}$. Thle li! na a i " " hole have been indicated by arrows. (c) SEM micrograph showing the britte nature 1, thit tra iur of a fiber and asso protuding, longish features, suggestive of the fibrilar nature of the fitber exposed to $300 \cdot \mathrm{C}$ for $200 \mathrm{~h}$. 
(a)

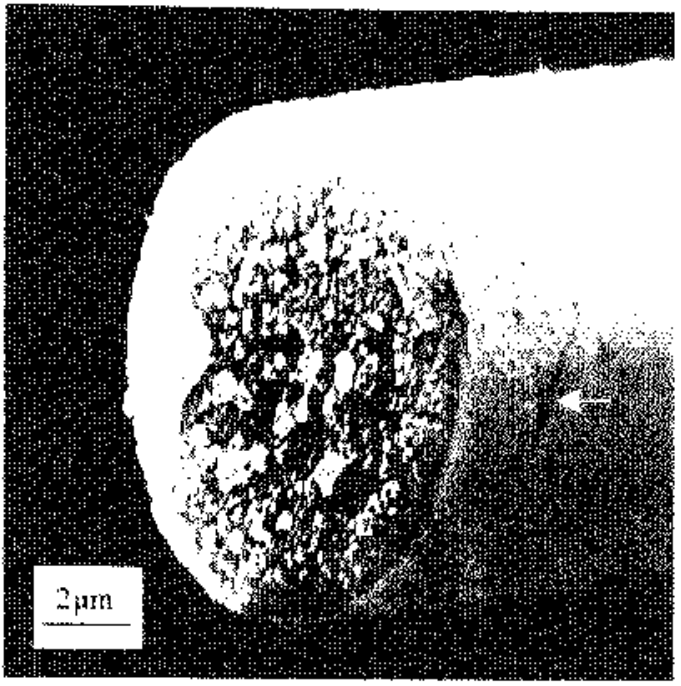

(b)

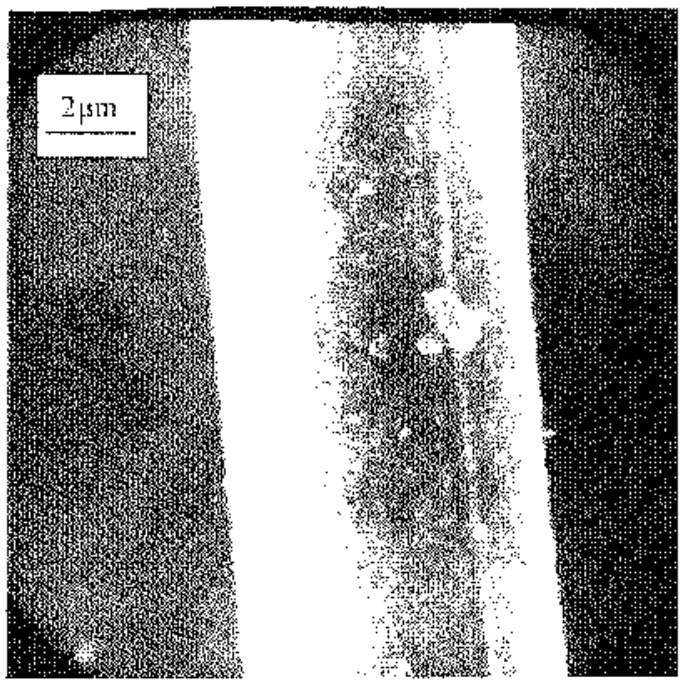

Figure 13. (a) SEM micrograph showirig holes and arc-like operings on the surface of a Twaron fiber exposed to 400 " $\mathrm{C}$ for $10 \mathrm{~h}$. (b) SEM micrograph showing material deposits on the sufface of a fiber exposed to $400^{\circ} \mathrm{C}$ for $10 \mathrm{~h}$. 


\section{A JAN aFd K. VIAYAN}
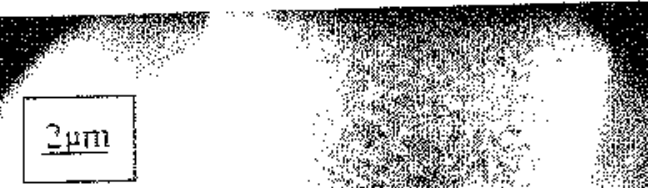

(a)

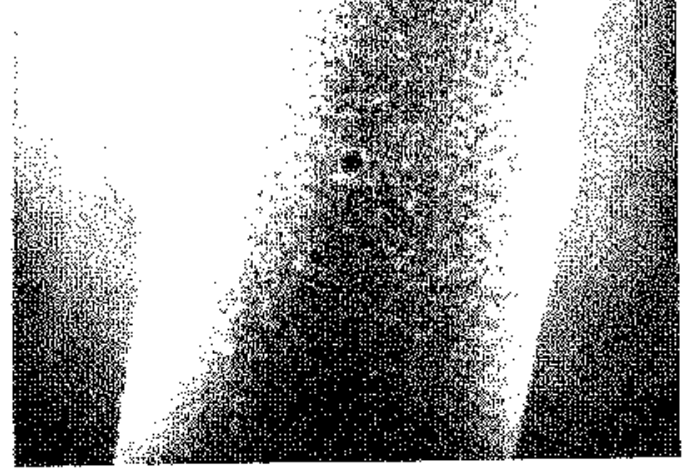

(b)

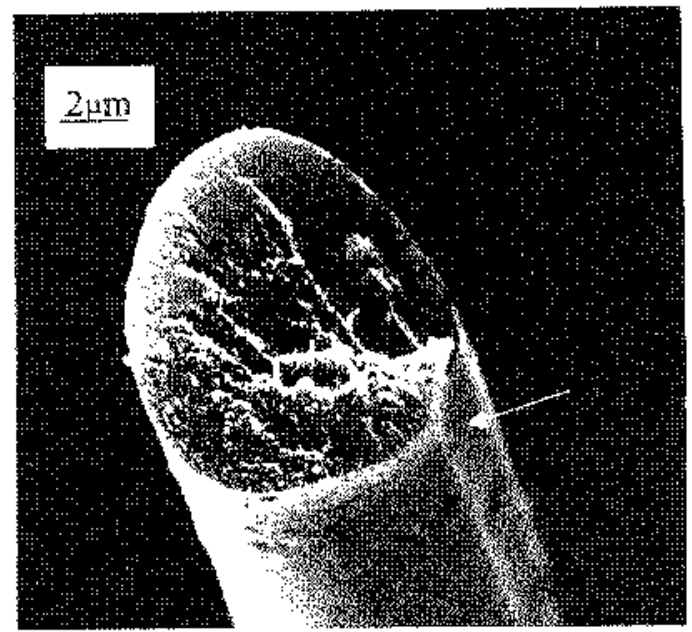

Figure 14. (a) SEM micrograph depicting the sponge-ike appearance of the surface of a fitber exposed to $450-\mathrm{C}$ tor 2.5 h. (b) SEM micrograpt depicting arc-like openings and a wrinkle (indicated by an arrow on the surtace of a tiber exposed to $450 \mathrm{C}$ for $2.5 \mathrm{~h}$. 
(a)

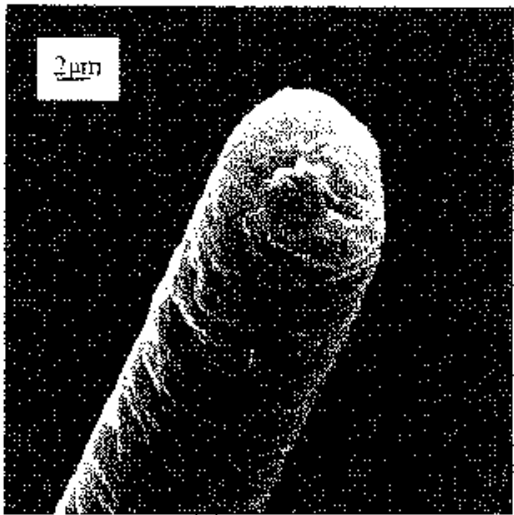

(b)
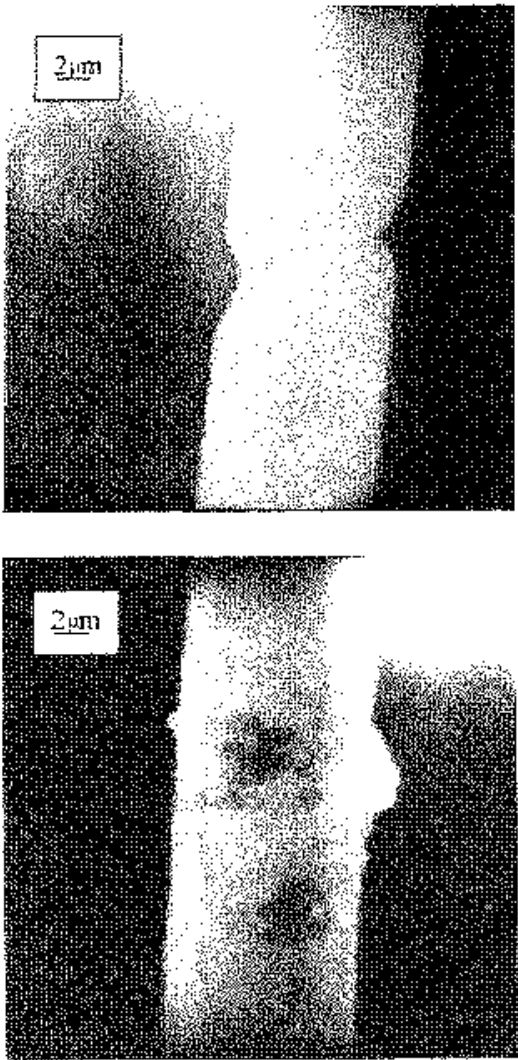

Figure 15. (a) SEM micrograpt depicting the scrubber wool-Hike appearance of the surface of a Twaron fiber exposed to 500 ' $C$ for 1 h. (b) SEM micrograph depicting an edge, which has been 'eaten away' in a fiber exposed to $500^{\circ} \mathrm{C}$ for $1 \mathrm{~h}$. (c) SEM nicrograph showing localized pits. 
Table 1. Possible correlations between thermally induced structural changes and initial tensile characteristics.

\begin{tabular}{ll}
\hline Observations & Implications \\
\hline Reduction in crystallinity & Reduction in tensile modulus \\
Sharpening of reflections & Growth of crystallites and/or reduction in \\
& microstrain; consequent increase in tensile \\
& modulus \\
Broadening of reflections & Reduction in crystallite size and/or increase \\
& in microstrain; consequent reduction in \\
& tensile modulus \\
Increase in azimuthal spread & Reduction in tensile modulus \\
Closing up of equatorial reflections & Reduction in tensile strength \\
Weight loss & Reduction in tensile strength \\
Surface damages & Reduction in tensile strength \\
\hline
\end{tabular}

\subsubsection{Comparison of the tensile properties of Twaron and Kevlar 49 fibers}

It may be pointed out that the tensile properties of the version of Twaron fibers used in this study are close to those of Kevlar 29 fibers. As such, the study is also comparing the thermal behaviors of Kevlar 29 and 49 fibres. Tensile data on identically aged Kevlar 49 and Twaron fibers were collected and we provide the details in this section.

In order to obtain a one-to-one comparison of the effect of thermal aging, Twaron and Kevlar fibers were aged at $150,250,300$ and $350^{\circ} \mathrm{C}$ for $1 \mathrm{~h}$, and values of the tensile modulus, tensile strength and percentage elongation at the break were estimated. Care was taken to ensure that, in both the cases, all the experimental conditions were identical. Figures 16(a)-(c) depict the effect of thermal exposure on the tensile strength, modulus and percentage elongation at the break of both fibers. In these figures, fractional values have been plotted as a function of temperature. Here, $S_{t}^{T}, M_{t}^{T}$, and $\varepsilon_{t}^{T}$ represent the values of strength, modulus and percentage elongation for fibers exposed to temperature $T$ for a duration of $t_{c u m}(T) . S_{0}, M_{0}$ and $\varepsilon_{0}$ are the corresponding values, prior to thermal exposure and are already listed in section 1 of this paper.

Figure 16(a) shows the variation of residual tensile strength with temperature. It is found that, until about $150^{\circ} \mathrm{C}$, there is practically no difference between the responses of the two types of fibers. However, beyond this stage, the reduction in the tensile strength of Twaron is more than that of Kevlar 49 fibers. For example, at $350^{\circ} \mathrm{C}$, after 1 hour of exposure, the residual strength of Kevlar is $\sim 65 \%$ of its initial value whereas for Twaron it is $\sim 26 \%$ of the initial value.

It must be pointed out that the observed variation in tensile strength conforms well with the earlier mentioned conclusions, which were drawn on the basis of X-ray, weight and SEM analysis (see Table 1).

Interestingly, the influence of $1 \mathrm{~h}$ of exposure on the tensile modulus is very different from that on tensile strength. With exposures to temperatures in the range $150-350^{\circ} \mathrm{C}$, both Twaron and Kevlar manifest improvement in the initial tensile modulus. As can be 


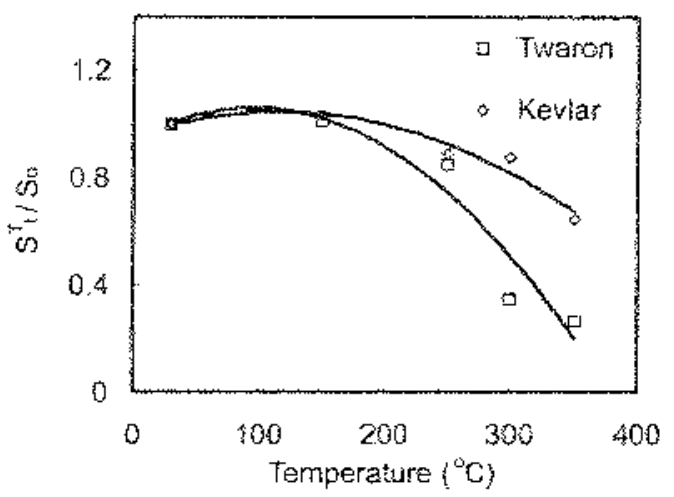

(a)

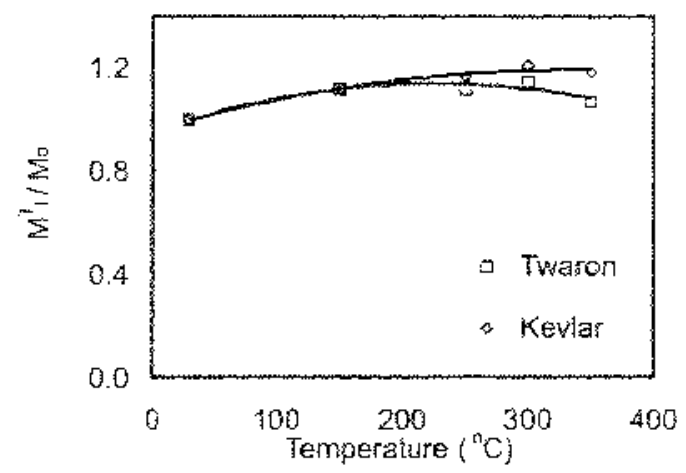

(b)

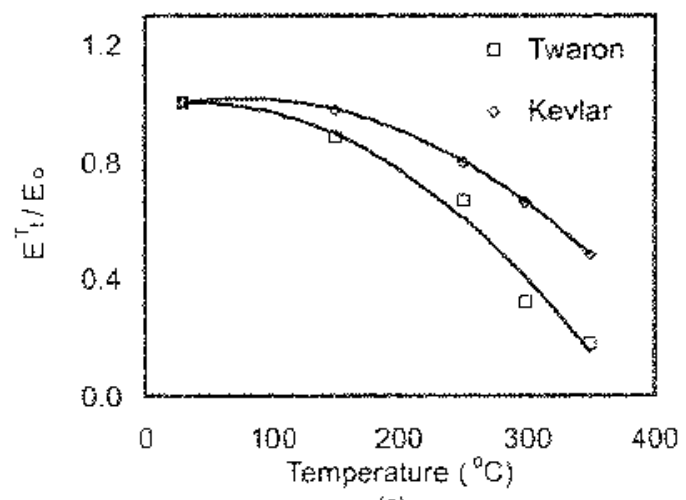

(c)

Figure $\$ 6$. Comparisons of the variations in (a) the tensile strength, (b) the tensile modulus and (c) the percentage elongation at the break of Twaron and Keviar. 
seen from figure $16(\mathrm{~b})$, at $150^{\circ} \mathrm{C}$, in the case of tensile modulus, there is no difference in the behavior of the two sets of similar fibers. However, with an increase in temperature, the difference between the behaviors turns out to be conspicuous and it increases progressively with temperature. At $350^{\circ} \mathrm{C}$, the increase in the initial modulus of Twaron is by $7 \%$ whereas for Kevlar it is by $18 \%$.

The observed increase in tensile modulus, however, deserves special comment. As indicated in table 1 , the sharpening of reflections observed in the early stages of thermal aging can contribute to an increase in the tensile modulus. However, other effects such as reduction in crystallinity and molecular misalignment have an opposite effect on the tensile modulus. The experimentally observed increase in modulus accompanying $1 \mathrm{~h}$ of exposure to various temperatures thus suggests that, at this stage of thermal aging, the effect of growth in crystallites and/or reduction in microstrain, as suggested by sharpening of reflections, overrides the adverse effects of molecular misalignment, reduction in crystallinity, etc., on the tensile modulus.

As in the case of tensile strength, the percentage elongation at the break decreases with aging. The extent of elongation is comparatively more for Twaron (figure 16(c)).

The comparative data obtained on identically aged Twaron and Kevlar 49 fibers prompts us to suggest that, although the two sets of fibers are made of the same polymer PPTA, fibers with improved initial properties are blessed with improved resistance to thermal exposure. This conclusion is indeed not meant to be in anyway derogatory about the Twaron fibers. Versions of Twaron fibers with properties close to those of Kevlar 49 are expected to have a comparable thermal behavior.

\section{CONCLUSIONS}

The thermal aging of Twaron fibers introduces both crystallographic and macro structural changes. The crystallographic changes include reduction in crystallinity, misalignment of polymer chains about the fiber axis, increase in the interlayer distance, changes in crystallite size and/or microstrain. The prominent macro structural changes are the introduction of surface holes, material loss and weight reduction. All the thermally induced effects in Twaron fibers are found to be influenced by the parameters $T$ and $t_{\text {cum }}(T)$. A one-to-one comparison of the tensile properties of identically aged Twaron and Kevlar 49 fibers indicates that the fiber with better initial properties has improved resistance to thermal exposure.

Acknowledgment. The authors acknowledge Akzo Nobelfor kindly providing with the Twaron fibers. They also thank Dr R. VKrishnan for the support. They acknowledge the help rendered by $D r N$. Balasubramanian and Mr Basavaraj of EternitEverest, India, for carrying out the tensile tests and by Dr T. A. Bhaskaran and Ms Kalavatifor recording the micrographs. 


\section{NOTE}

1. Author to whom any correspondence should be addressed.

\section{REFERENCES}

[1] Schuster D 1992 Technical Research Centre of Finland (ITT) p. 233

[2] Fitzer E, Kompalik D and Kunz M 1986Deutsche Keramischen GesellschafiE. I. p. 847

[3] Hindeleh A M and Abdo Sh M 1989 Polymer 30218

[4] Shubha M 1989 M. Phil. Thesis Mangalore University, India

[5] Parimala H V 1991 M. Phil. Thesis Mangalore University, India

[6] Parimala H V and Vijayan K 1993 J. Mater. Sci. Lett. 1299

[7] Iyer R V and Vijayan K 1994 Polymer Science Recent Advances I. S. Bhardwaj, ed. (New Delhi: Allied Publishers) Vol. 1, p. 362

[8] Iyer R V and Vijayan K 1998 Macromolecules New Frontiers K. S. V Srinivasan, ed. (New Delhi: Allied Publishers) Vol. 2, p. 847

[9] Iyer R V and Vijayan K 1998 Curr. Sci. 75946

f 10] Iyer R V and Vijayan K 1999 Bull. Mater. Sci. 221013

[11] Iyer R V and Vijayan K 2000 J. Mater. Sci. 355731

[12] Iyer R V 1999 Ph.D. Thesis Bangalore University, India

[13] Jain A and Vijayan K 2000 Curr. Sci. 18331

[14] Linda L C 1998 Handbook of Composites S. T. Peters, ed. (London: Chapman \& Hall) p. 206

[15] Bearden J A 1933 Phys. Rev. 4392

[16] Alexander L E 1974 X-ray Diffraction Methods in Polymer Science (New York: Wiley Interscience) Ch. 3

[17] Northolt M G 1974 Em Polym. J. 10799

[18] Shubha M, Parimala H V and Vijayan K 1993 J. Mater. Sci. 1260

[19] Kalashnik A T, Panikarova N P, Dovbh Ye V, Kozhina G V Kalmykova V D and Papkov S P 1978 Polym. Sci. USSR 193173

[20] Fitzgerald J A and Irwin R S 1991 The Royal Society of Chemistry p. 392 